\title{
Uma Abordagem Sistemática de Modelagem de Processos para a Investigação de Problemas em Sistemas de Informação: Aplicação em uma Central de Regulação Médica
}

\author{
Alan P. Souza, João V. V. B. Freitas, \\ Amauri M. Cunha, Maria Luiza M. Campos
}

Programa de Pós-Graduação em Informática (PPGI-IM/NCE) - Universidade Federal do Rio de Janeiro (UFRJ)

Caixa Postal 2324 CEP: 20.001-970 - Rio de Janeiro - RJ - Brasil

\{alanpsouza, jvfreitas.freitas\}@gmail.com,

\{amauri, mluiza\}@nce.ufrj.br

\begin{abstract}
Emergency services for pre-hospital attendance are designed to provide quick mechanisms for medical care. These services, in general, have some kind of computational system to support their activities and to register executed tasks. This paper presents an approach that explores detailed process modeling to identify and to analyze problems in an information system and its use in a medical regulation center of a large city. The results obtained in implementing the approach show its applicability and encourage its testing in other domains.
\end{abstract}

Resumo. Os serviços de emergência para Atendimento Pré-Hospitalar têm como objetivo prover mecanismos ágeis de assistência médica. Estes serviços, em geral, possuem algum tipo de sistema computacional para suporte à execução das suas atividades e ao registro dos atendimentos efetuados. Este artigo apresenta uma abordagem que utiliza a modelagem detalhada de processos na identificação e análise de problemas existentes no sistema de informação e em seu uso em uma Central de Regulação Médica de uma grande metrópole. Os resultados obtidos com a execução da abordagem mostram sua aplicabilidade e encorajam a sua experimentação em outros domínios.

\section{Introdução}

Levantamentos e pesquisas diversas apontam que muitos dos óbitos associados a acidentes ou ocorrências de emergência médica poderiam ser evitados se houvesse algum atendimento médico logo nos primeiros instantes após a ocorrência do evento [Elliot 2000]. O tempo de atendimento a uma vítima é um fator crítico para a sobrevivência, especialmente em situações traumáticas. Por esta razão, justifica-se a busca por mecanismos que acelerem o processo de atendimento. Para atender a estas necessidades, diversos serviços de Atendimento Pré-Hospitalar já foram criados há algum tempo, sendo alguns destes modelos reconhecidos mundialmente ${ }^{1}$. No Brasil, estes serviços para o atendimento a eventos de urgência e emergência foram instituídos

\footnotetext{
${ }^{1}$ Alguns destes serviços existem há décadas, com destaque para aqueles adotados na França (Service d'Aide Medicale d'Urgence) e nos Estados Unidos (Emergency Medical Services Systems Act).
} 
mais recentemente ${ }^{2}$, quando o Ministério da Saúde decidiu implantar um componente pré-hospitalar móvel em municípios e regiões de todo o país [Ministério da Saúde 2006a].

Este trabalho é fruto de um projeto que tem como objetivo propiciar melhorias aos atendimentos oferecidos por um serviço pré-hospitalar de uma metrópole nacional, através do desenvolvimento e implantação de soluções baseadas em tecnologias de informação.

A abrangência deste projeto vai desde o tratamento das solicitações telefônicas, a fim de melhorar a produtividade operacional do sistema, passando pelo estudo da cognição humana nos postos de trabalho em situações de urgência, até ao processo de gerenciamento dinâmico das ambulâncias e suas equipes de atendimento associadas.

Entretanto, este trabalho se concentra em minorar a dificuldade de processamento das demandas telefônicas de atendimento de urgência na Central de Regulação Médica, devido a possíveis problemas do sistema computacional utilizado. $\mathrm{O}$ objetivo principal é reduzir o tempo de registro das informações provenientes de uma ocorrência no software de apoio às atividades do serviço pré-hospitalar.

Por ser um serviço recente no sistema de saúde brasileiro, as dificuldades enfrentadas pelos agentes humanos que operam o sistema computacional de apoio à central de atendimento são visíveis, havendo muitas reclamações de que o mesmo provoca atrasos no tratamento das solicitações telefônicas no atendimento de urgências médicas.

A fim de identificar causas para os problemas apresentados, a equipe de projeto realizou um trabalho de campo para levantar o processo de trabalho de todos os operadores da Central de Regulação Médica, incluindo a avaliação dos sistemas informacionais utilizados. O estudo exploratório de campo, composto de entrevistas com pessoas específicas envolvidas no serviço, utilizou como base a metodologia preconizada por Thiollent (2003).

Seguindo as propostas de Cunha e Souza $(2005,2006)$, através da utilização do conceito de memória, buscou-se rastrear os recursos utilizados, de modo a adquirir uma ampla compreensão das atividades executadas. Com a análise dessas atividades identificaram-se problemas na concepção e na utilização do sistema computacional, assim como outros oriundos de procedimentos inadequados de trabalho humano [Crandall, Klein e Hoffman 2006]. Foi possível também uma revisão dos modelos conceituais de dados, que forneceu auxílios para a estruturação e organização das fontes de dados e elaboração de um ambiente analítico. A abordagem e os resultados evidenciados nesta publicação são uma versão estendida daqueles apresentados em [Souza et al. 2009].

Este tipo de trabalho é voltado para o levantamento detalhado de processos envolvendo as pessoas que operam a Central de Regulação Médica, utilizando a suposição largamente aceita de que esta é uma forma adequada de estudar os sistemas informacionais de apoio ao trabalho humano [Sharp e McDermott 2001].

\footnotetext{
${ }^{2}$ Os serviços de Atendimento Pré-Hospitalar foram definidos através da portaria $n^{\circ} 1.864$, de 29 de setembro de 2003.
} 
As sucessivas visitas à central de regulação deste serviço de Atendimento PréHospitalar foram essenciais para a coleta de uma boa variedade de evidências, visto que o serviço de emergência está situado em um contexto amplo e complexo, que inviabilizaria sua compreensão fora da conjuntura na qual ocorre.

Outro aspecto interessante é que esses encontros permitiram o estabelecimento de relações de confiança com os diferentes profissionais envolvidos no serviço ${ }^{3}$, o que foi fundamental para melhorar a aceitação do estudo investigativo. Apesar do ritmo das atividades na central de regulação ser intenso e desgastante para cada um dos profissionais envolvidos, essas características pouco afetaram o andamento do estudo, pois a maior parte dos levantamentos foi realizada junto aos chefes de operação e equipes de apoio; os profissionais diretamente envolvidos no atendimento das ocorrências foram pouco exigidos.

Para evitar o ceticismo por parte dos indivíduos que foram alvo da pesquisa com relação às teorias, métodos e outros elementos valorizados pelo espírito científico [Thiollent 2003], a cada passo dado no desenvolvimento do estudo, os profissionais do serviço foram sendo apresentados, de maneira gradual, às diversas técnicas que estavam sendo utilizadas.

Este artigo inclui além desta introdução outras cinco seções descritas a seguir. $\mathrm{Na}$ seção 2 apresenta-se o contexto dos serviços de Atendimento Pré-Hospitalar. A seção 3 discute o referencial teórico, evidenciando como a modelagem de processos pode ser favorável $\mathrm{n}$ a investigação de problemas em sistemas de informação. A abordagem utilizada é detalhada na seção 4 e os resultados obtidos a partir de sua aplicação estão na seção 5. Finalmente, apresentam-se as conclusões na seção 6 .

\section{Serviço de Atendimento Pré-Hospitalar (APH)}

O Atendimento Pré-Hospitalar compreende qualquer assistência médica realizada fora do âmbito hospitalar, provendo assistência e transporte adequado até algum serviço de saúde, devendo este procedimento ser efetuado somente por profissionais especializados [Junior e Valente 2005].

Lopes e Fernandes (1999) consideram APH como toda assistência realizada, de forma direta ou não, fora do âmbito hospitalar, através dos diversos meios e métodos disponíveis, com uma resposta adequada à solicitação de socorro, tendo como objetivo a manutenção da vida e/ou a minimização das seqüelas.

Segundo o Conselho Federal de Medicina [apud Ministério da Saúde 2006b], uma Emergência é a constatação médica de condições de agravo à saúde que impliquem em risco iminente de vida ou sofrimento intenso e que exijam, portanto, tratamento médico imediato. Urgência é a ocorrência imprevista de agravo à saúde com ou sem risco potencial de vida, cujo portador necessita de assistência médica imediata.

Este serviço envolve uma equipe de profissionais de saúde preparada para atender ao paciente da melhor maneira possível, contando também com o suporte

\footnotetext{
${ }^{3}$ Durante as visitas realizadas todos os membros da equipe do projeto estabeleceram diálogos com os mais diferentes papéis associados ao serviço: coordenadores, administradores, auxiliares técnicos, supervisores, tele-atendentes, médicos reguladores, operadores de frota, etc.
} 
especializado de tele-atendentes, operadores de frota, condutores de ambulância, etc. A Figura 1 sumariza o processo relacionado ao serviço de Atendimento Pré-Hospitalar.

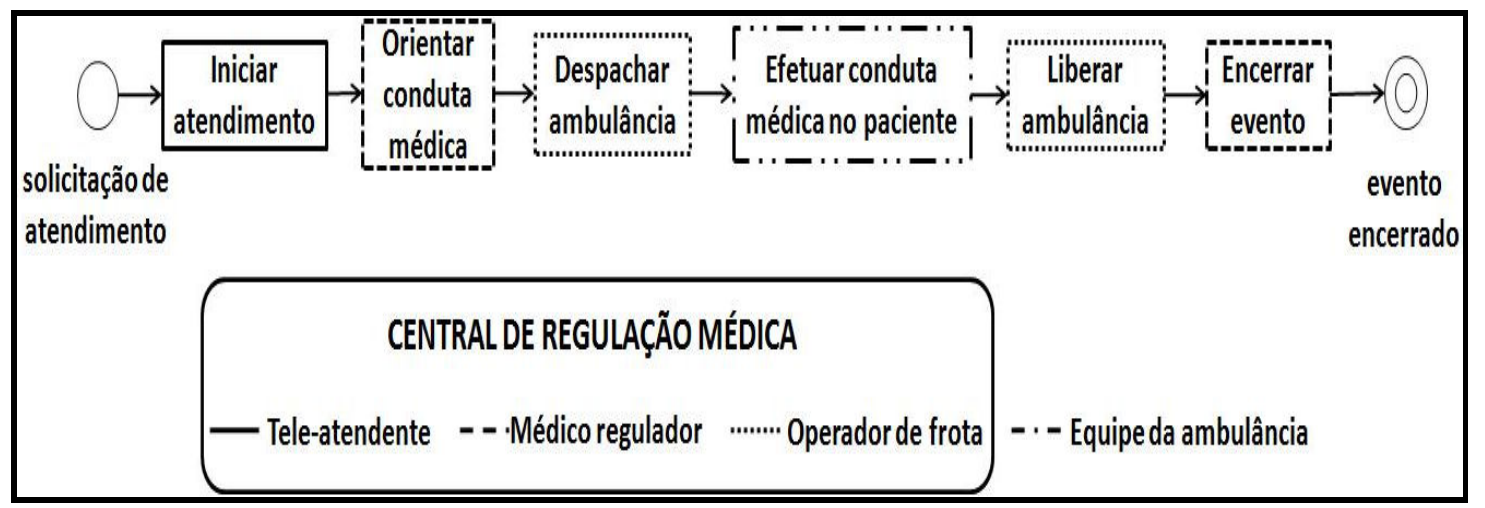

Figura 1 - Fluxo de atividades simplificado relativo ao atendimento de uma ocorrência.

O processo tem início com o recebimento de uma solicitação de socorro por telefone. Neste momento, um tele-atendente realiza de maneira concomitante o registro de dados do evento e a triagem de possíveis ligações inadequadas (trotes, enganos, etc.).

Caso a ligação seja considerada apropriada, ela é transferida para um médico regulador responsável por realizar a avaliação do cenário clínico. Nesta etapa, o médico realiza o diagnóstico do paciente, decidindo pelo envio ou não de uma ambulância para o local da ocorrência [Borsato et al. 2006].

O médico regulador pode dar um conselho, uma orientação, ou deslocar uma equipe com médico, enfermeiro e equipamentos de uma UTI. A liberação de cada recurso depende da necessidade específica de cada ocorrência. Em caso positivo, um operador de frota é incumbido da alocação e despacho do tipo de ambulância correspondente (à gravidade do evento).

A equipe de socorro, quando enviada ao local da ocorrência, submete o paciente a condutas médicas, onde pode ser identificada ou não a necessidade de se transferir o paciente para uma unidade de saúde.

Ao término do atendimento, a equipe da ambulância deve comunicar ao operador de frota a conclusão do procedimento. Este profissional deve liberar a ambulância associada ao atendimento, para que o médico regulador possa, eventualmente, determinar a ocorrência como encerrada.

\section{Modelagem de Processos para Investigação de Problemas em Sistemas de Informação}

Dentro do contexto deste projeto de pesquisa, a modelagem de processos foi utilizada tanto para a equipe de pesquisadores absorverem conhecimentos sobre os procedimentos adotados na Central de Regulação Médica e, principalmente, para investigar problemas existentes no sistema de informação utilizado.

Aliada à construção dos modelos de processos, outra técnica bastante valiosa é o destaque dos recursos que são manipulados ao longo do fluxo de atividades, identificando os insumos necessários para a execução de uma determinada atividade e os resultados provenientes do cumprimento desta. A relevância desses elementos 
informacionais, denominados memórias, foi destacada no trabalho de Cunha e Souza (2006). Eles podem ser visualizados na Figura 2 deste artigo.

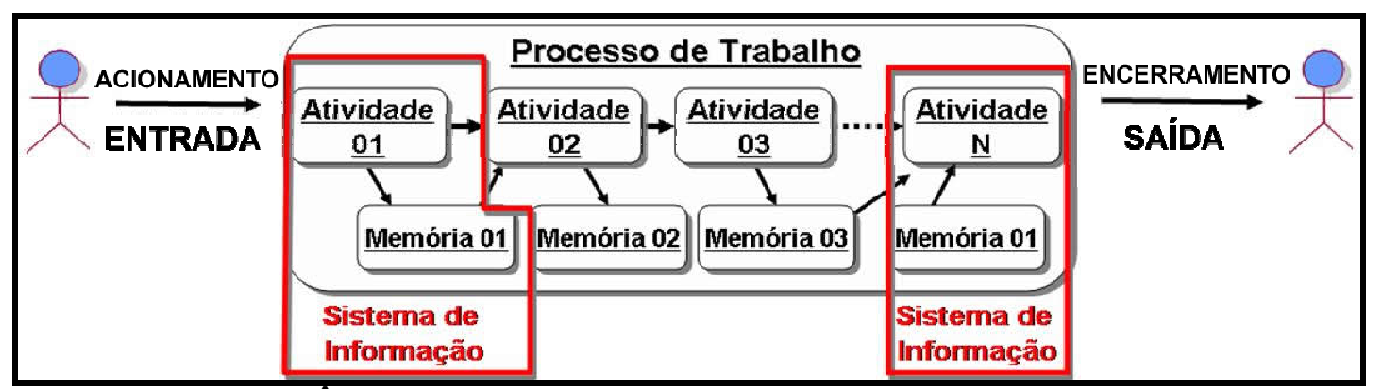

Figura 2 - Ênfase do conceito de memórias no modelo de processos de negócios identificando as atividades que terão apoio de TI, adaptado de [Cunha e Souza 2006].

Uma memória representa qualquer informação gerada e armazenada em um meio persistente ${ }^{4}$ da organização para ser consultada ou atualizada posteriormente com algum objetivo pelas atividades do processo [Cunha e Souza 2006].

Outra vantagem da utilização do conceito de memória é a possibilidade de reconhecer informações desnecessárias. Isto ocorre quando a memória é criada por uma atividade e não é utilizada por nenhuma outra atividade dos processos existentes.

$\mathrm{Na}$ literatura não foram encontrados trabalhos relevantes que abordam especificamente a utilização da modelagem de processos para a identificação de problemas em sistemas computacionais. A maioria dos estudos envolve a utilização da modelagem de processos no levantamento de requisitos com a finalidade de elaboração de casos de uso [Jacobson, Ericsson e Jacobson 1994; Sharp e McDermott 2001]. Além do mais, estas propostas não utilizam a explicitação das memórias envolvidas em cada uma das atividades do processo.

O RUP (Rational Unified Process) apresenta os artefatos em sua estrutura, que são os elementos que mais se assemelham ao conceito de memória. Nele, os artefatos representam insumos e produtos no processo, gerados ou consumidos durante a execução de uma atividade [Rational Unified Process 2000]. O seu ponto negativo, para sistemas de urgência como o que estamos tratando, é o fato de desconsiderar como artefato os elementos informacionais que não estejam armazenados em algum tipo de relatório. Assim, comunicações verbais relevantes para o processo podem não ser levadas em conta. Esta limitação está presente também nos estudos originais de Cunha e Souza (2006). Além disso, o RUP foi concebido unicamente para o processo de desenvolvimento de software, e não para processos genéricos de trabalho.

Outra abordagem conhecida é a ARIS [Davis 2008] que é composta de vários modelos de processos que podem ser expressos em vários tipos de diagramas, com diferentes representações dos recursos informacionais envolvidos na execução de uma atividade. Entretanto, essas representações não consideram de forma explícita o conceito de memória utilizado nesse trabalho.

Com base neste referencial teórico a equipe de projeto promoveu a modelagem de processos, rastreando as informações utilizadas ao longo do fluxo de atividades, e

\footnotetext{
${ }^{4}$ Esses meios persistentes podem ser os bancos de dados da organização, arquivos em formato texto ou planilhas, além de documentos em papel, livros de anotações, etc.
} 
identificando os recursos computacionais e humanos responsáveis pelo seu manuseio. A proposta desenvolvida neste projeto é descrita na próxima seção, onde a abordagem utilizada é apresentada com mais detalhes.

\section{Abordagem Adotada}

Esta seção apresenta o levantamento realizado para identificar problemas existentes nas atividades executadas dentro da Central de Regulação Médica. Descreve-se a seguir uma visão geral das condições iniciais e da abordagem utilizadas no trabalho, além do seu detalhamento.

Como evidência da existência de problemas, pode ser mencionado o não cumprimento do tempo máximo desejado para um serviço de atendimento de urgência [Elliot 2000]. Sendo assim, o principal desafio foi identificar os problemas existentes no sistema computacional vigente. Para isso utilizaram-se os modelos de processos de trabalho dos operadores da central, associados ao conceito de memória como base para uma investigação sobre o software de aplicação. A Figura 3 ilustra as condições iniciais adotadas e objetivos que se esperam alcançar neste trabalho.

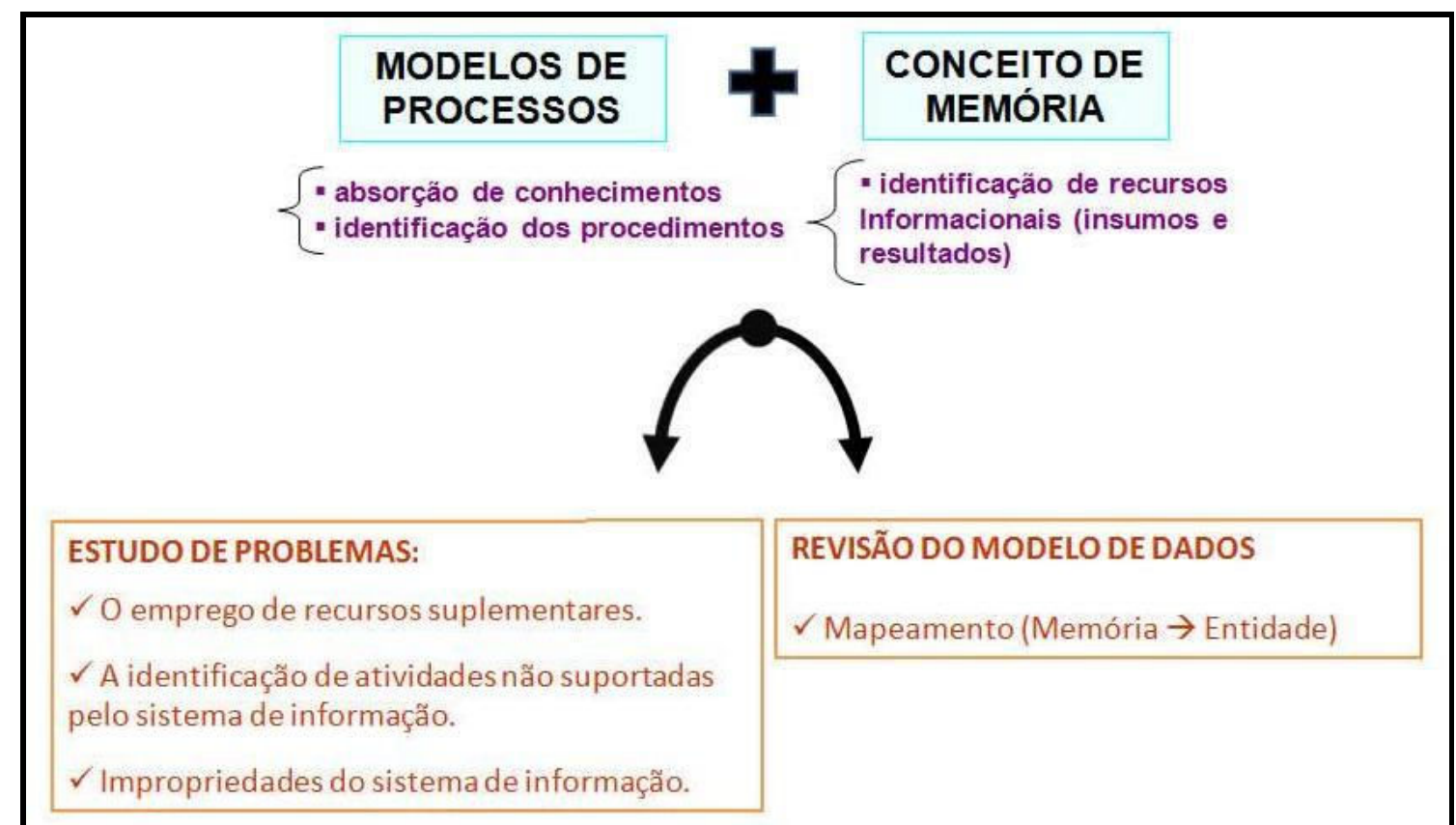

Figura 3 - Modelos de processo e conceito de memória para investigação de problemas em sistemas de informação.

Os modelos de processos contribuíram na absorção de conhecimentos sobre o domínio de Atendimento Pré-Hospitalar (APH) e na identificação dos procedimentos adotados na Central de Regulação Médica. A integração com o conceito de memória favoreceu o reconhecimento dos recursos informacionais utilizados em cada atividade $\mathrm{e}$ em qual meio persistente eles se encontravam armazenados.

Os resultados a serem obtidos com esta abordagem são uma revisão dos modelos de dados, por intermédio de um mapeamento entre as memórias organizacionais ressaltadas nos modelos de processos e as classes dos modelos de dados, além da geração de um relatório de inadequações associadas ao sistema computacional. 
A Abordagem para investigação de problemas em sistemas de informação contém seis etapas, conforme representado na Figura 4. As primeiras quatro etapas coleta de dados, análise de dados, estruturação do conhecimento e modelagem de dados, ocorrem de forma iterativa para cada um dos processos de trabalho. As duas etapas que seguem estão associadas ao estudo dos problemas encontrados e à proposta de soluções para os mesmos. Esta última etapa contempla parte da evolução da abordagem comparada àquela destacada em [Souza et al. 2009].

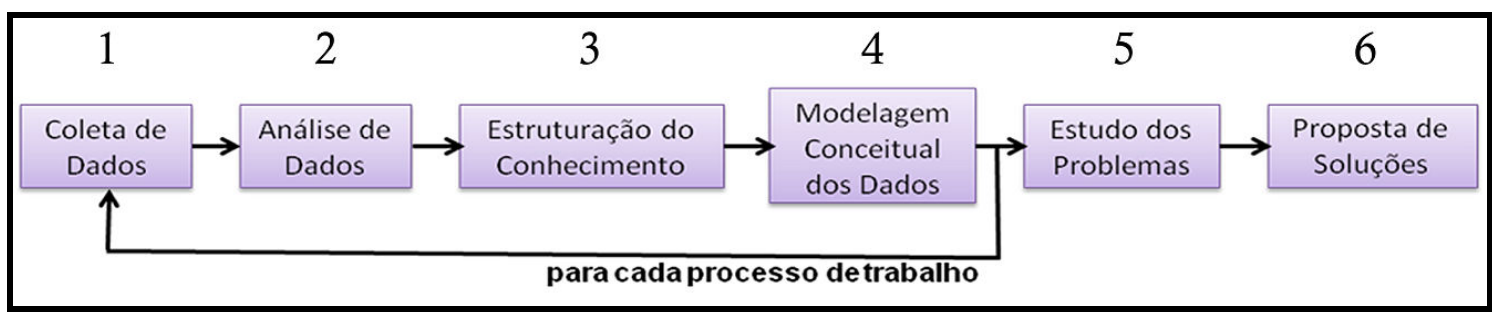

Figura 4 - Abordagem para investigação de problemas em sistemas de informação.

O Quadro 1 apresenta uma visão mais detalhada da abordagem proposta.

Quadro 1 - Abordagem para investigação de problemas em sistemas de informação.

\section{Coleta de Dados}

i. Estudo da documentação existente, tendo como objetivo o entendimento do domínio de conhecimento da organização.

ii. Observação in loco da execução do processo de trabalho.

iii. Entrevistas com profissionais chaves para o processo de trabalho.

\section{Análise de Dados}

i. Compreensão detalhada do Processo de Trabalho
a. Papéis associados à execução das atividades do processo de trabalho.
b. Insumos e produtos relacionados às atividades.
c. Suporte computacional de apoio à execução das atividades.
d. Recursos utilizados como apoio à execução do processo (Formulários suplementares, planilhas em meio computacional, etc.)

ii. Elaboração do Glossário de Termos

iii. Análise inicial dos Problemas relacionados ao Suporte Computacional
a. Atividades que não possuem suporte computacional.
b. Atividades que possuem suporte computacional, mas com dependência de recursos suplementares.

3. Estruturação do conhecimento a respeito dos Processos de Trabalho

i. Modelagem do processo de trabalho
a. Eventos associados ao início e término do processo, além de eventos temporais associados ao mesmo.
b. Papéis responsáveis pela execução das atividades do processo de trabalho.
c. Atividades do processo de trabalho com seus respectivos insumos e resultados.
I. Incluindo atividades que representem repetições.
d. Pontos de decisão presentes no processo de trabalho.

ii. Revisão do Glossário de Termos

4. Modelagem Conceitual dos Dados baseada nas Memórias Organizacionais.

i. Especificação das memórias organizacionais presentes no processo de trabalho, independentemente do meio onde estejam persistidas.

ii. Análise do relacionamento existente entre as memórias organizacionais identificadas no processo de trabalho.

iii. Revisão do Modelo Conceitual de Dados a partir das Memórias Organizacionais especificadas e seus relacionamentos (estrutura). 
Repetir os passos de 1 a 4 para cada um dos processos de trabalho identificados

5. Estudo dos Problemas relacionados ao Suporte Computacional nas atividades de cada um dos processos de trabalho

i. Atividades que consomem ou produzem memórias organizacionais, mas não possuem suporte computacional.

ii. Atividades que possuem suporte computacional, mas as memórias organizacionais consumidas ou produzidas não são contempladas.

iii. Atividades com suporte computacional inadequado, onde as memórias organizacionais não são contempladas de forma apropriada.

\section{Proposta de Soluções}

i. Detalhamento dos problemas associados a cada uma das atividades dos processos, destacando adaptações e impactos.

ii. Recomendações gerais e sugestões sobre funcionalidades do sistema computacional.

iii. Estruturação e organização das fontes de dados.

Como resultados das atividades de campo foram gerados diferentes tipos de documentos para cobrir necessidades de diferentes etapas do projeto ${ }^{5}$. Dessa forma, a equipe de trabalho ficou mais capacitada para formular hipóteses de melhorias ou ao menos fazer progredir a consciência quanto à existência de obstáculos para $o$ funcionamento satisfatório do serviço.

Inicialmente foram realizados encontros da equipe do projeto com coordenadores e profissionais envolvidos nas atividades do serviço, tendo como objetivo a aquisição de um conhecimento básico sobre o fluxo de atividades do processo completo de regulação médica, nos próprios locais onde as atividades são executadas. A partir daí, de maneira gradual, através da análise das entrevistas gravadas, do estudo das apostilas de treinamento do sistema computacional e da avaliação dos formulários manuais preenchidos, os pesquisadores passaram a elaborar vários modelos de processos, juntamente com novas versões de todos os documentos utilizados.

A cada semana, novas reuniões eram agendadas na central de regulação com os profissionais apropriados de modo que estes pudessem validar as documentações produzidas. As discussões que surgiam agregavam sempre novos conhecimentos, correções e sugestões para os documentos e relatórios do projeto.

$\mathrm{Na}$ modelagem de processo, os papéis atuantes em cada uma das atividades foram discriminados visualmente através do uso de piscinas e raias, além disso, para cada uma das atividades, os insumos e resultados ${ }^{6}$ associados foram evidenciados através do conceito de memória [Cunha e Souza 2006]. Os diagramas de processos construídos ressaltavam ainda, através de códigos identificadores, em qual tipo de meios persistentes essas memórias se encontravam (por exemplo, se em sistema computacional, formulário em papel, comunicação verbal, etc.). A discriminação de códigos representa uma das principais características que foram agregadas ao conceito de memória. Esse aspecto permitiu uma análise mais profunda do domínio,

\footnotetext{
5 Em suas diferentes etapas, a abordagem aplicada gerou diversos tipos de documentos, entre eles: diagramas de processos com insumos e resultados das atividades, mapas conceituais, glossários de termos, dicionários e modelos de dados, etc.

${ }^{6}$ Insumo é tudo aquilo que uma atividade precisa obter de seu exterior para ser completamente realizada e gerar suas saídas. Resultado é tudo aquilo que a atividade emite para o seu exterior durante a sua execução [Cunha e Souza 2006].
} 
especialmente na identificação das comunicações verbais existentes na Central de Regulação Médica, que representaram um desafio em razão da sua elevada freqüência e importância nas atividades de regulação do serviço de Atendimento Pré-Hospitalar.

A comunicação entre os profissionais, as decisões, os processos temporais, enfim, todos os aspectos que foram classificados como relevantes para a futura identificação dos problemas e as suas causas foram de alguma forma registrados nos modelos. A Figura 5 mostra uma pequena parte de um dos modelos de processos, evidenciando estes aspectos.

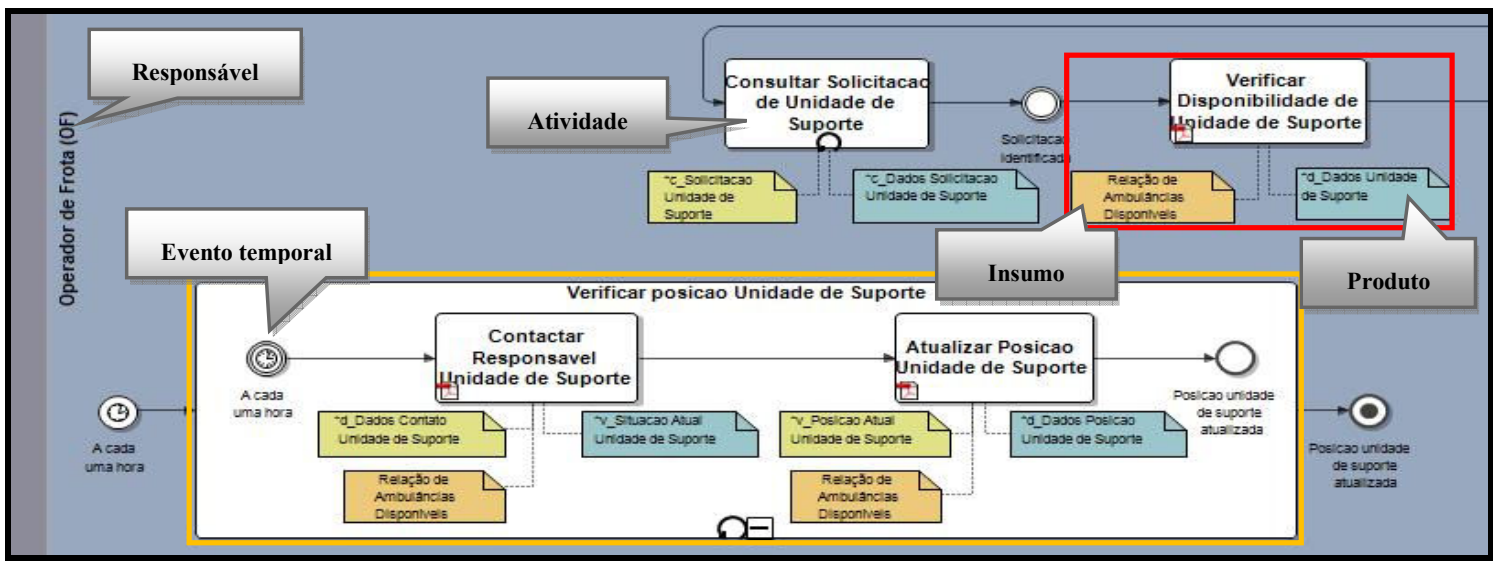

Figura 5 - Parte de um modelo do processo de atendimento do serviço de Atendimento PréHospitalar adotado na Central de Regulação Médica (Ferramenta: Intalio BPMS Designer ${ }^{7}$.

Em paralelo, foram gerados mapas conceituais ${ }^{8}$ e glossários de informações refletindo aquilo que era representado nos modelos, visando representar o conhecimento obtido. Toda a documentação elaborada passou por reuniões de aprovação até se atingir um detalhamento definido como satisfatório para as atividades do projeto.

\section{Resultados Obtidos}

Os resultados obtidos neste estudo estão baseados nas orientações contidas nos modelos de processos de trabalho do domínio de Atendimento Pré-Hospitalar e transferência inter-hospitalar, detalhados através da proposta de caracterização de atividades definida em Cunha e Souza (2006), o que possibilitou a representação de todos os insumos e produtos dos mesmos, sendo estes informacionais, materiais ou verbais.

\footnotetext{
${ }^{7}$ Intalio BPMS Designer é uma plataforma de código aberto para modelagem de processos que utiliza o padrão BPMN (Business Process Modeling Notation) [Object Management Group 2008]. A ferramenta está disponível para download em http://www.intalio.com/products/bpm/downloads/.

8 Mapa conceitual é um diagrama (ou grafo direcionado) que possui nós e associações. Os nós representam conceitos do domínio, onde cada conceito pode ser expresso por uma palavra, algumas palavras ou até mesmo símbolos. Os conceitos são relacionados através das associações.
} 


\subsection{Estudo de Problemas}

Através deste detalhamento foi possível iniciar uma análise das inadequações do sistema de informação e dos problemas de utilização do mesmo, listados a seguir:

\section{O emprego de recursos suplementares}

Um dos primeiros resultados obtidos através desta análise foi a identificação do uso excessivo de papel em atividades já suportadas pelo sistema de informação, como a utilização em paralelo de formulários em papel na persistência de informações necessárias à execução do processo, provocando uma redundância de dados.

Este fato ocorre devido à desconfiança quanto ao desempenho do sistema de informação, principalmente em relação aos seus requisitos não funcionais de confiabilidade e desempenho [Sommerville 2003]. Esta prevenção é justificada pelas eventuais interrupções apresentadas pelo sistema, tendo como conseqüência um maior esforço das pessoas e a utilização maior de recursos materiais durante a execução das atividades.

A utilização destes formulários resultou no desenvolvimento de base de dados que tentam "espelhar" a estrutura de dados contida nos mesmos, sendo povoadas a posteriori por uma equipe de digitadores. A necessidade deste registro subseqüente representa um acréscimo nos custos associados à execução do processo, além da replicação e inconsistência dos dados registrados nestas diversas bases, já que elas não são integradas e possuem diferentes representações dos conceitos do domínio da aplicação.

\section{A identificação de atividades não suportadas pelo sistema de informação}

A modelagem do processo de trabalho possibilitou o reconhecimento de atividades não apoiadas pelo sistema de informação. Um exemplo desta situação é o controle realizado de forma manual pelos operadores de frota $(\mathrm{OF})$ em relação à disponibilidade das ambulâncias e à disposição das mesmas nas bases geográficas de estacionamento, devido à inexistência dessas funcionalidades no sistema de informação.

Como forma de suprir essa limitação, outro conjunto complementar de documentos em papel foi elaborado e passou a ser utilizado, tendo como objetivo registrar o conjunto de ambulâncias disponíveis.

Esses formulários são atualizados diariamente por recursos especialmente alocados para tal fim, tendo como resultado um maior esforço na execução destas atividades e insegurança quanto à utilização dos dados, uma vez que eles são disponibilizados em papel.

\section{Inadequações do sistema de informação}

O levantamento dos processos de trabalho também possibilitou a identificação de atividades onde as funcionalidades do sistema de informação representavam algum tipo de "gargalo" para a execução do processo. Esta situação foi percebida quando da necessidade de se encerrar um atendimento realizado com o auxílio de uma ambulância.

Idealmente, o responsável pela comunicação na ambulância deveria informar ao operador de frota sobre a conclusão do atendimento, permitindo ao mesmo liberar a 
ambulância no sistema, retornando-a para a lista de ambulâncias livres, e comunicar ao médico regulador responsável a possibilidade de encerrar o atendimento no sistema de informação.

Contudo, o médico regulador não possui permissão para encerrar um atendimento que ainda possua uma ambulância associada e se vê impossibilitado de proceder tal tarefa enquanto o término das comunicações entre a ambulância e o operador de frota não forem formalizadas no sistema computacional.

Além disso, devido ao fato de o sistema de informação não oferecer uma forma automática de comunicação quando da liberação das ambulâncias, o número de atendimentos aguardando fechamento, mas já terminados na prática, passam a representar parte dos atendimentos em execução, trazendo alguma sobrecarga ao funcionamento do sistema de informação. Esta situação contribui para as eventuais interrupções do sistema. Estas questões são detalhadas em um relatório formatado conforme a Tabela 1 .

Tabela 1 - Parte do Relatório de Questões.

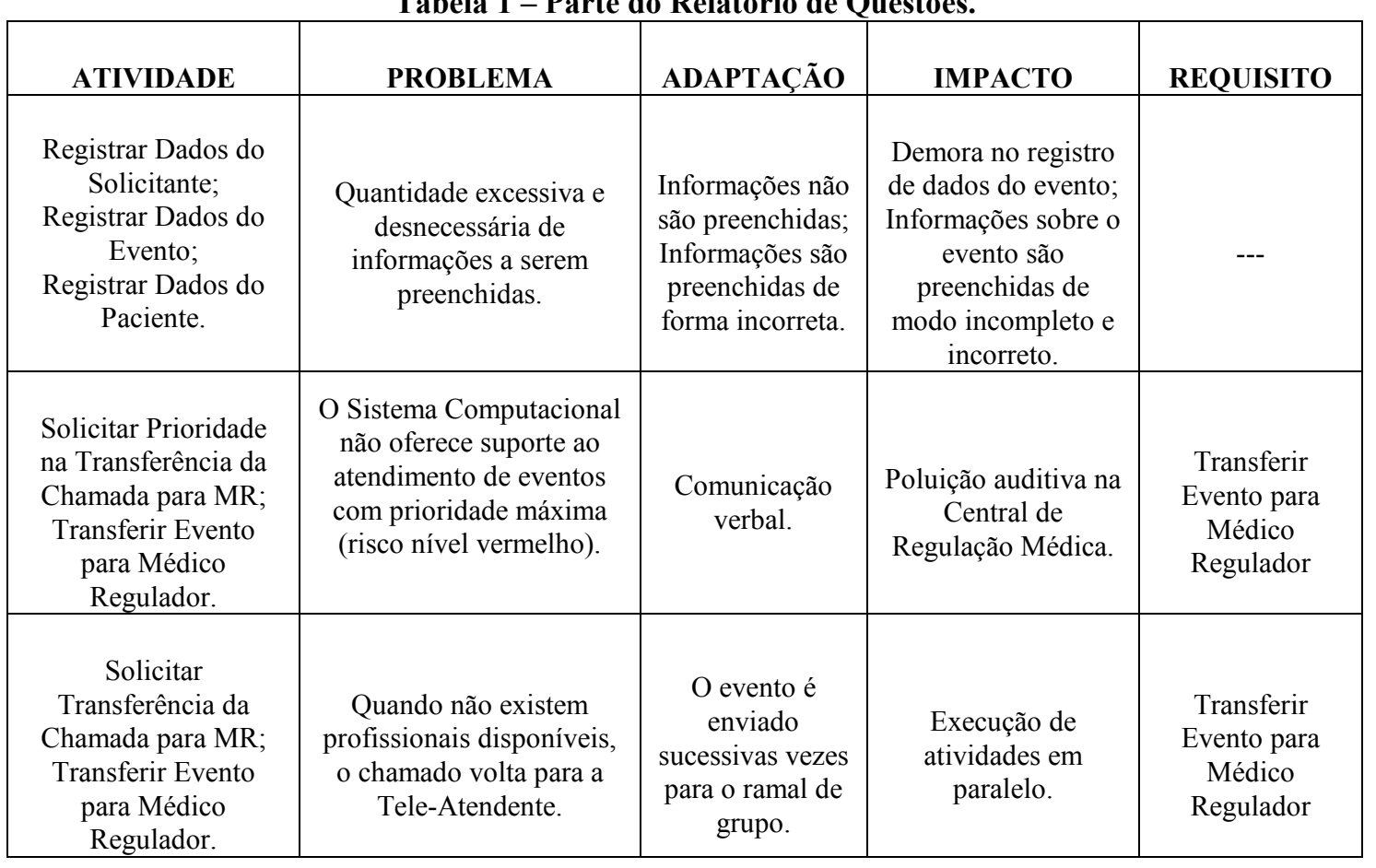

Cada um dos problemas explicitados no relatório de questões possui uma análise detalhada, indicando em qual processo o problema reside, em qual atividade e por qual agente humano é executada.

O relatório descreve a ação prescrita que deveria ser executada (to be) e a adaptação que é feita para se contornar o problema existente (as is), assim como o impacto que é gerado para o processo quando as atividades não são executadas de acordo com as suas especificações.

Para cada um dos problemas existentes são feitas algumas recomendações. Estas podem ser, por exemplo, uma revisão da estrutura do banco de dados ou da arquitetura do sistema computacional quando questões de desempenho são as que merecem um tratamento mais apurado. 
Quando as atividades não são suportadas pelo sistema computacional ou a funcionalidade existe sem o suporte adequado, a recomendação aponta para a especificação ou a modificação de um requisito.

Quando a recomendação é a especificação de um novo requisito, um Caso de Uso é elaborado pela equipe do projeto para dar conta deste requisito. Quando a recomendação é a modificação de um requisito existente também é elaborado um novo requisito, em razão da falta de acesso da equipe de projeto à documentação de requisitos existentes no sistema de informação da Central de Regulação Médica.

O Quadro 2 apresenta o exemplo de uma destas análises para um problema identificado e o Caso de Uso referente ao requisito recomendado para o problema.

Quadro 2 - Análise dos problemas identificados

\section{Ramal de Grupo}

Quando um chamado é enviado para o ramal de grupo dos Médicos Reguladores, após alguns segundos, caso não haja profissionais disponíveis para efetuar a regulação do evento, o chamado volta para a Tele-Atendente.

Q NOME DO PROCESSO: Atendimento Geral

$\checkmark$ NOME DA ATIVIDADE NO PROCESSO: Solicitar Transferência da Chamada para Médico Regulador; Transferir Evento para Médico Regulador;

$\checkmark$ ATORES ENVOLVIDOS: Tele-Atendente

$\checkmark$ AÇÃO PRESCRITA: O evento é enviado sucessivas vezes para o ramal de grupo.

У ADAPTAÇÃO: nenhuma

Q IMPACTO: execução de atividades em paralelo; demora no atendimento a eventos.

๑ RECOMENDAÇÃO: criação de uma funcionalidade no sistema, mantendo os chamados na fila de prioridades aguardando atendimento.

$\square$ REQUISITO: Transferir Evento para Médico Regulador

Caso de Uso

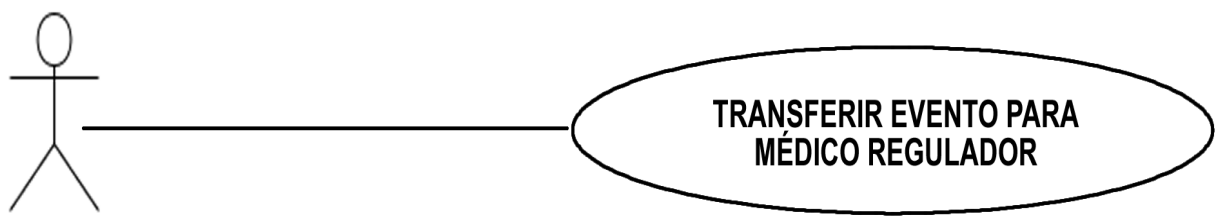

TELE-ATENDENTE

- ATOR:

Tele-Atendente

- PRÉ-CONDIÇÃO:

A Tele-Atendente avalia a chamada telefônica como adequada.

- ROTEIRO: 


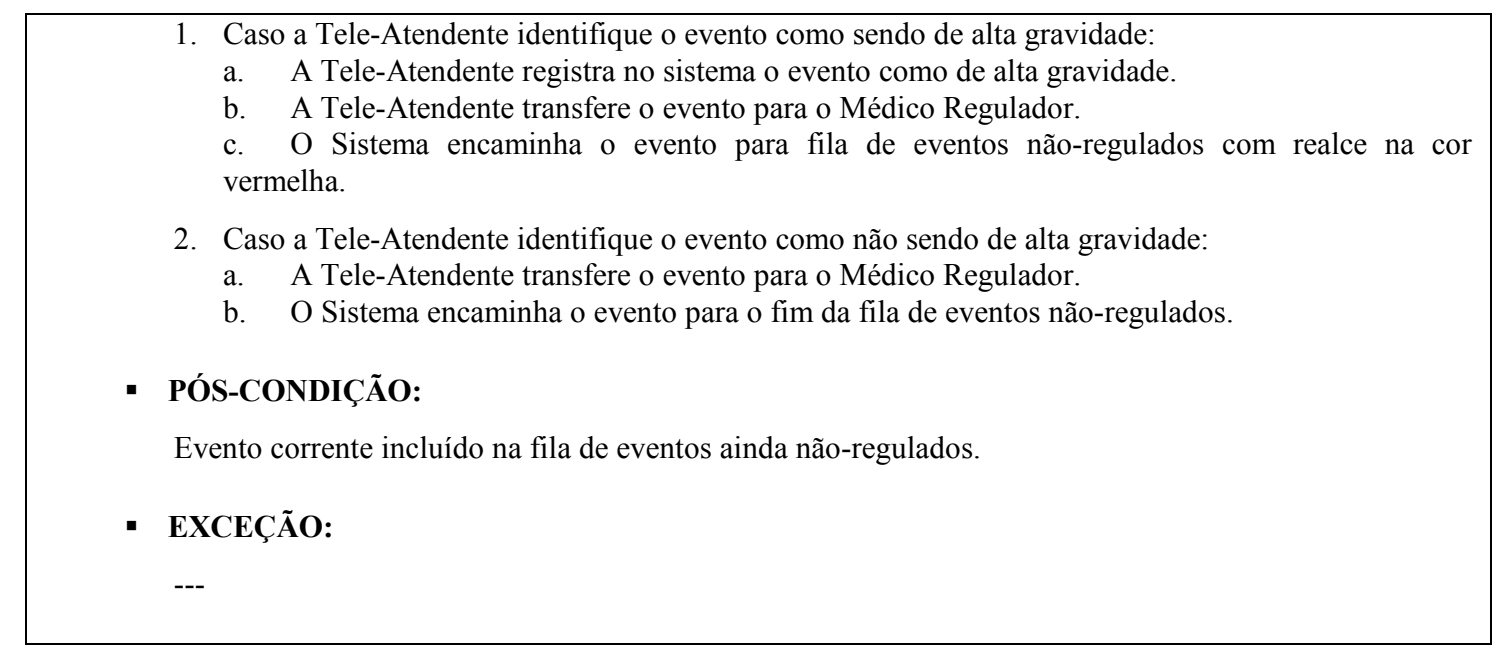

Vale ressaltar que o objetivo da proposta é a identificação de problemas em sistemas de informação e não a definição de requisitos de sistema. Contudo, percebe-se que essa etapa também é beneficiada, em virtude do estudo detalhado do processo contemplado nessa abordagem.

\subsection{Revisão do Modelo de Dados}

Outro resultado obtido com a aplicação da proposta de processo de trabalho está relacionado à análise do modelo conceitual de dados. Como citado anteriormente, informações refletindo aquilo que era representado nos processos de trabalho foram documentadas em glossários e mapas conceituais, de modo a gerar relatórios de suporte para aumentar o conhecimento em construção sobre o domínio de APH. Todos os termos representados nos modelos de processo de trabalhos e documentados no glossário e mapas conceituais apresentam descrições bastante ricas.

Os mapas conceituais foram a representação encontrada para atingir estes objetivos, em razão da sua expressividade e facilidade de construção. Estes diagramas foram mais úteis na fase inicial do projeto durante o conhecimento geral do domínio, uma vez que auxiliaram na compreensão dos conceitos, fatos, princípios e tipos de eventos que ocorriam na Central de Regulação Médica.

Novak e Cañas (2006) destacam a grande expressividade dos mapas conceituais, em razão de sua flexibilidade permitir uma naturalidade de representação com proximidade conceitual e de notação do problema e da linguagem, propiciando facilidades para se entender o que foi especificado e evitando ambigüidades. A Figura 6 mostra um exemplo de mapa conceitual utilizado para a visualização dos dados computacionais envolvidos no atendimento das ocorrências. 


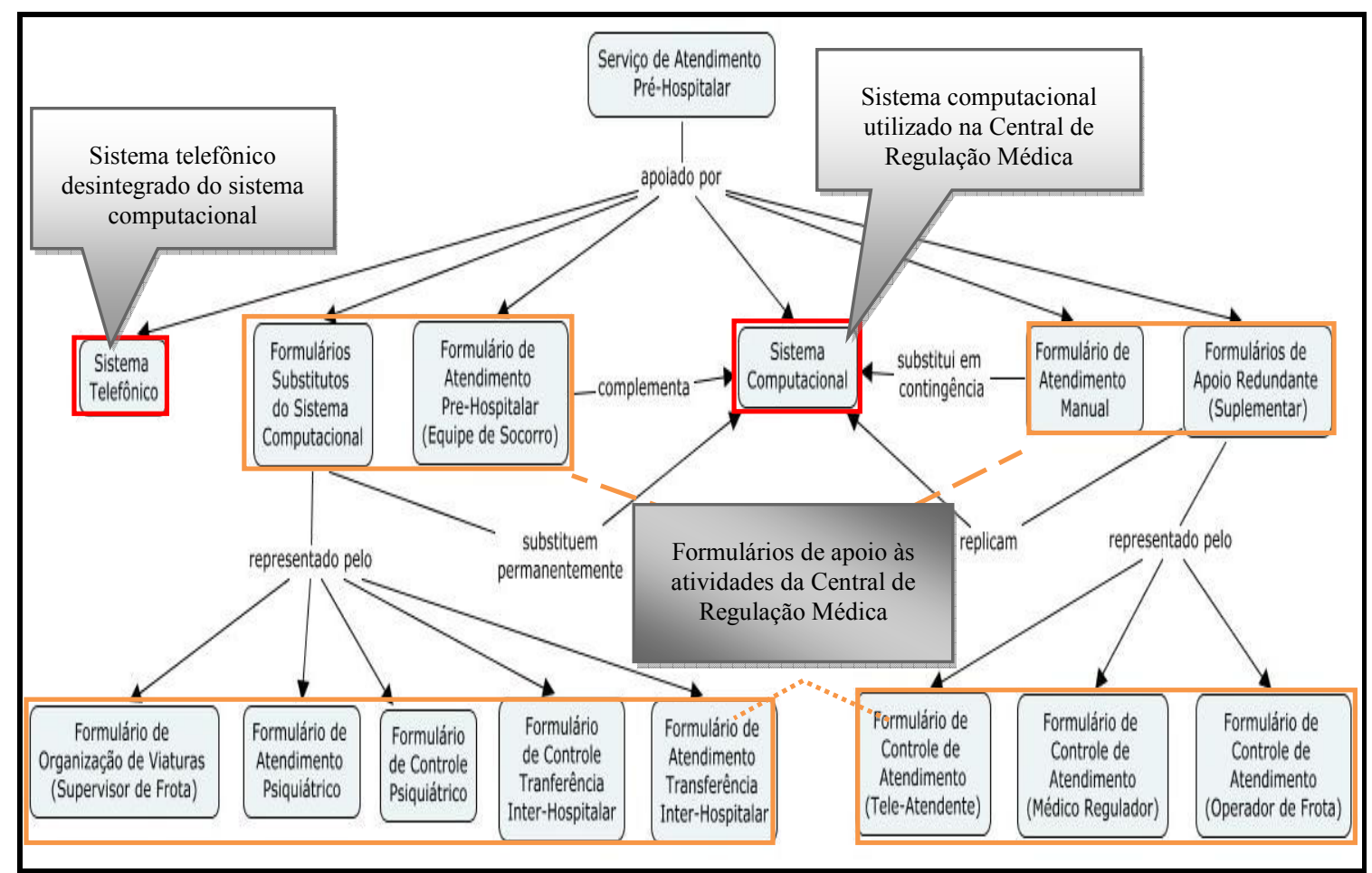

Figura 6 - Mapa conceitual que evidencia relação do sistema computacional com os demais recursos que o apóiam no atendimento das ocorrências na Central de Regulação Médica.

Por outro lado, os glossários foram úteis na definição de termos importantes associados às políticas nacionais de atenção e regulações médicas de urgência ou quaisquer outros termos específicos dos procedimentos adotados pelos profissionais na Central de Regulação Médica.

Da mesma forma que em outros cenários, o glossário foi muito importante na compreensão dos termos e para que houvesse um consenso sobre a terminologia utilizada no domínio. Todos os termos que surgiam durante a modelagem, especialmente aqueles associados às memórias dos processos, foram definidos $\mathrm{e}$ validados paralelamente com especialistas do domínio. Os glossários foram mais importantes nas fases intermediárias e finais do projeto em razão da sua riqueza de detalhes. A Tabela 2 mostra uma parte do glossário com a descrição de campos que são preenchidos no Formulário de Atendimento Manual e de que forma estes estão relacionados com os termos do domínio.

Tabela 2 - Trecho de um documento contendo a descrição de campos a serem preenchidos no Formulário de Atendimento Manual.

\begin{tabular}{|c|l|}
\hline Termo & \multicolumn{1}{c|}{ Descrição } \\
\hline $\begin{array}{c}\text { Avaliação Inicial e } \\
\text { Motivo }\end{array}$ & $\begin{array}{l}\text { Campo do quadro de Dados da Regulação Médica, onde ficam registradas } \\
\text { observações sobre a avaliação inicial sobre o estado e/ou sintomas do paciente, bem } \\
\text { como fica registrado também o motivo da incidência do mesmo (atropelamento, } \\
\text { colisão, queda, dispnéia, etc.). }\end{array}$ \\
\hline $\mathbf{N}^{\mathbf{0}}$ Evento & $\begin{array}{l}\text { Campo do quadro de Dados Iniciais da Ocorrência, onde fica registrado o número do } \\
\text { evento que está sendo atendido. Este número é seqüencial (por ordem de evento) e } \\
\text { reiniciado diariamente (período de 24 horas). }\end{array}$ \\
\hline
\end{tabular}

Dessa forma, esta proposta utiliza os mapas conceituais e glossários como forma de gerar mecanismos na organização do conhecimento e permitir também a 
identificação de problemas por intermédio da rastreabilidade entre os dispositivos de software. A compreensão dos pontos de interação entre os diferentes elementos do domínio são muito importantes para qualquer tentativa de solução dos problemas existentes.

Para [Pfleeger 2004], a viabilidade das mudanças deve ser avaliada conforme os impactos delas nos demais artefatos. Estas implicações são determinadas pelo estudo da rastreabilidade existente entre os artefatos de mesmo tipo (rastreabilidade vertical) e de tipos diferentes (rastreabilidade horizontal).

A partir destes elementos, foi possível desenvolver modelos conceituais que detalham o conjunto de dados pertencentes ao domínio (memórias), assim como os seus relacionamentos. As memórias utilizadas em várias atividades, independentemente do meio em que eram persistidas ou por quais papéis eram manipuladas, representam conceitos de maior importância dentro do domínio relacionado ao processo de trabalho.

Portanto, estes elementos informacionais devem ser mapeados como uma entidade do modelo conceitual de dados, pois estes estão ou pelo menos deveriam estar associados a alguma funcionalidade do sistema computacional que suporta o processo de trabalho.

Sendo assim, o estudo integrado desses modelos permite uma análise detalhada dos problemas do sistema, auxiliando o reconhecimento das funcionalidades relevantes, inadequadas ou desnecessárias. A Figura 7 apresenta um exemplo do mapeamento de uma memória identificada no processo de trabalho, com sua definição especificada no Glossário de termos do domínio, para uma entidade do modelo conceitual de dados.

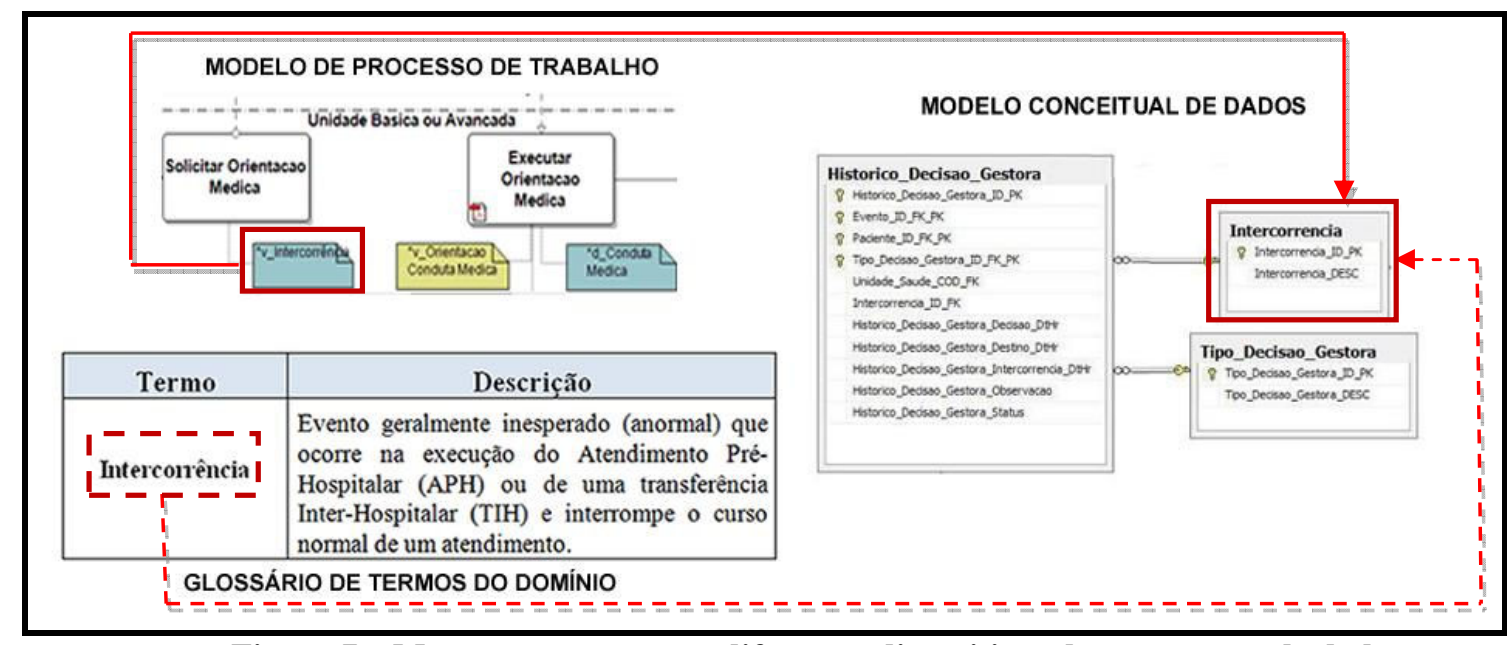

Figura 7 - Mapeamento entre os diferentes dispositivos de tratamento de dados.

Além disso, a utilização conjunta do conceito de memória na revisão do modelo conceitual de dados e da modelagem de processos possibilitou um estudo mais criterioso das necessidades informacionais da Central de Regulação Médica.

$\mathrm{Na}$ literatura encontram-se algumas abordagens com objetivo de mapeamento entre processos e dados, dentre as quais, podemos citar o trabalho de Cappelli et al. (2007) que visa o desenvolvimento de ontologias de domínio a partir da modelagem de processo. Entretanto essas não foram utilizadas, uma vez que as mesmas não viabilizariam a associação desejada com as memórias especificadas nos modelos de 
processo de trabalho, de modo alcançar os objetivos desejados para o domínio de estudo específico e em tempo hábil.

\subsection{Ambiente Analítico}

Não está no escopo deste trabalho o detalhamento da construção do ambiente analítico a partir da análise dos problemas identificados nos modelos de processo e da revisão dos modelos de dados. Contudo, vale ressaltar a viabilidade da utilização dos resultados obtidos com esta abordagem na especificação de análises para o suporte à tomada de decisão.

Neste sentido, este estudo teve como objetivo a identificação de todas as fontes de informação necessárias à execução do processo de APH, análise dos problemas estruturais apresentados pelas mesmas (replicação de dados, registros nulos, etc) e modelagem de uma base de dados intermediária (Operational Data Store (ODS)), onde tais informações são mantidas de forma integrada, limpa e transformada.

O estudo ainda contempla a análise estatística das fontes de informações e a definição das regras de transformação necessárias quando da carga da base de dados intermediária. Um exemplo de resultado que pode ser obtido através deste estudo, pode ser visualizado no Quadro 3.

Quadro 3 - Mapeamento das fontes de informações para o ODS.

\begin{tabular}{|c|c|c|c|c|c|c|c|c|}
\hline \multicolumn{9}{|c|}{$\begin{array}{l}\text { Descrição: Esta e } \\
\text { o atendimento de um event } \\
\text { permanecer no local, dentre } \\
\text { Atributos: }\end{array}$} \\
\hline \multirow{2}{*}{\multicolumn{4}{|c|}{$\begin{array}{c}\text { DE } \\
\text { TransporteDS }\end{array}$}} & \multirow{2}{*}{\multicolumn{5}{|c|}{$\begin{array}{c}\text { PARA } \\
{[\mathrm{APH}] .[\mathrm{dbo}] . \text { Tipo_Decisao_Gestora }}\end{array}$}} \\
\hline & & & & & & & & \\
\hline \multicolumn{4}{|c|}{ Coluna } & \multicolumn{5}{|c|}{ Coluna } \\
\hline Nome & Tipo & & NULL & Nome & Tipo & & /FK & NULL \\
\hline TransporteID & int & & $\begin{array}{l}\text { not } \\
\text { null }\end{array}$ & Tipo_Decisao_Gestora_ID_P & int & & $\mathrm{K}$ & $\begin{array}{l}\text { not } \\
\text { null }\end{array}$ \\
\hline TransporteDS & $\begin{array}{c}\text { nvarchar } \\
(100)\end{array}$ & & null & Tipo_Decisao_Gestora_DESC & $\begin{array}{c}\text { nvarchar } \\
(100)\end{array}$ & &. $\mathrm{a}$ & null \\
\hline RegAtivo & $\begin{array}{l}\text { nvarchar } \\
\text { (1) }\end{array}$ & & null & - & - & & - & - \\
\hline- & - & & - & DW_CONTROLE_Origem & $\begin{array}{c}\text { nvarchar } \\
(50)\end{array}$ & &. $\mathrm{a}$ & null \\
\hline- & - & & - & DW_CONTROLE_DTHR & datetime & &. $\mathrm{a}$ & null \\
\hline \multicolumn{9}{|c|}{ Estatísticas: } \\
\hline \multicolumn{9}{|c|}{ Número de registros da tabela: 11} \\
\hline Coluna & \multicolumn{2}{|c|}{$\begin{array}{l}\text { Valores } \\
\text { Null }\end{array}$} & $\begin{array}{c}\text { Fora } \\
\text { Domínio }\end{array}$ & Valors Mínimo/Máximo & $\begin{array}{r}\text { Tamanho } \\
\text { Mínimo/Máx }\end{array}$ & & \multicolumn{2}{|c|}{ Observações } \\
\hline TransporteID & \multicolumn{2}{|l|}{0} & 0 & $1 / 90$ & $1 / 2$ & & \multicolumn{2}{|c|}{ n.a. } \\
\hline TransporteDS & \multicolumn{2}{|l|}{0} & 0 & $\begin{array}{c}\text { *** NÃO ENQUADRADO } \\
\text { EM DECISÃO PADRÃO } \\
\text { ***/UTILIZAR }\end{array}$ & \multicolumn{2}{|l|}{$16 / 30$} & \multicolumn{2}{|c|}{ n.a. } \\
\hline
\end{tabular}




\begin{tabular}{|c|c|c|c|c|c|}
\hline & & & $\begin{array}{c}\text { TRANSPORTE PRÓPRIO / } \\
\text { TERCEIROS }\end{array}$ & & \\
\hline RegAtivo & 0 & 0 & $1 / 1$ & $1 / 1$ & n.a. \\
\hline
\end{tabular}

Transformação:

- T1. Esta coluna será relacionada com a tabela...

- T2. Este mapeamento deverá...

O Quadro 3 apresenta o mapeamento da memória relacionada às decisões tomadas pelo médico regulador durante o APH. No mesmo estão especificadas as informações necessárias ao processo de extração, carga e transformação dos dados que serão persistidos no $O D S$.

Entre as possibilidades de análise disponíveis a partir da criação deste ambiente, pode-se destacar a visualização dos dados por diferentes perspectivas e a geração flexível de relatórios gerenciais. A Figura 8 ilustra a geração de um relatório através do ambiente analítico, tendo como foco o atendimento por tipo de evento. Os resultados apresentados neste relatório contêm valores alterados propositalmente, de modo a cumprir acordos de confidencialidade firmados junto ao serviço de Atendimento PréHospitalar quanto ao sigilo de suas informações. Este procedimento agrega segurança sobre os dados, porém sem interferir na compreensão dos relatórios gerados.

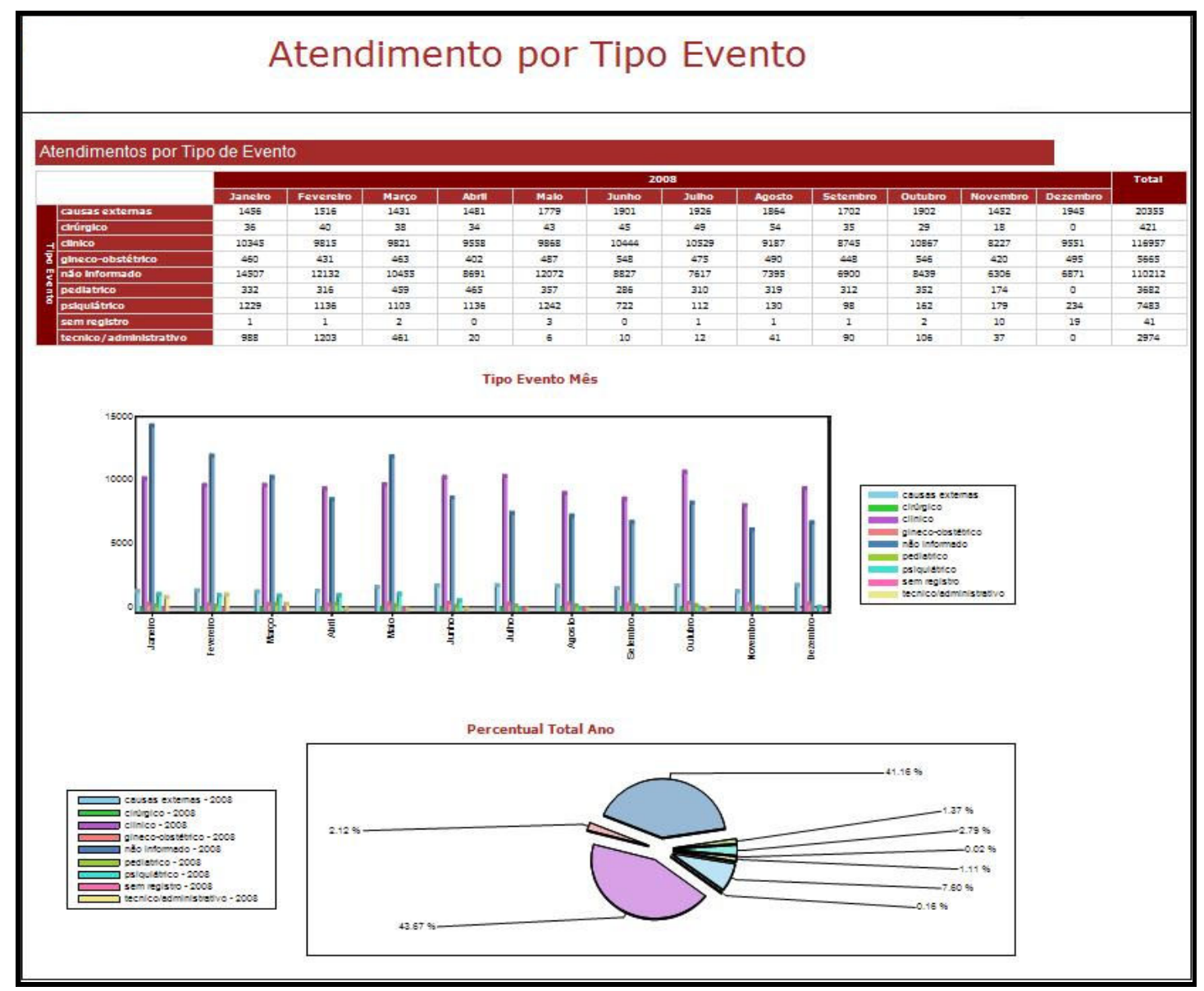

Figura 8 - Relatório gerado através do ambiente analítico. 
$\mathrm{Na}$ próxima seção serão apresentadas as conclusões obtidas a partir deste trabalho, assim como suas limitações e possibilidades para trabalhos futuros.

\section{Conclusões}

A identificação de inadequações e problemas de utilização de um sistema de informação não é uma atividade trivial, pois envolve a análise de aspectos técnicos, humanos e organizacionais, além da relação entre eles. No domínio relacionado ao Atendimento Pré-Hospitalar esta análise torna-se ainda mais complexa, dado o stress envolvido na sua execução.

Neste sentido, foi possível observar que a abordagem apresentada na seção 4 mostrou-se adequada na identificação de impropriedades e problemas de utilização do sistema de informação apontados na seção 5.1 deste artigo.

Outro aspecto a ser ressaltado é a utilização do conceito de memória como forma de caracterização dos processos de trabalho e de suas respectivas atividades, pois através deste conceito foi possível identificar um número considerável de elementos informacionais e materiais associados aos processos. Além disso, por meio do uso do conceito de memória foi possível identificar algumas distorções, tais como:

- Atividades que apresentavam tratamento redundante de informações, com o emprego de recursos suplementares (formulários, por exemplo) aos existentes no sistema computacional;

- Atividades com necessidade de tratar informações relacionadas ao domínio, mas que não eram suportadas pelo sistema de informação;

- Atividades suportadas pelo sistema de informação, porém com as memórias não contempladas;

- Atividades suportadas pelo sistema de informação inadequadamente e memórias contempladas inapropriadamente.

Além destes resultados de âmbito mais técnico, foi possível observar que os modelos de processos de trabalho podem apoiar a realização de treinamentos dos funcionários envolvidos nas atividades da Central de Regulação Médica. A aquisição do conhecimento seria facilitada, pois os modelos de processo, além de representarem de maneira adequada como as atividades devem ser executadas, possuem ainda um forte apelo visual, que confere destaque às responsabilidades que cada papel possui dentro do fluxo de atividades, assim como os recursos informacionais associados a cada atividade.

As próximas etapas do estudo são a validação do Relatório de Questões e a implantação de suas recomendações na Central de Regulação Médica. A validação do Relatório de Questões junto aos responsáveis pelo serviço de APH é um procedimento primordial para a apropriada implantação das recomendações especificadas neste documento. Por intermédio destas, acredita-se que seja possível obter uma redução no tempo de registro das informações provenientes de uma ocorrência, uma vez que as recomendações corrigem aspectos críticos do sistema de informação e procedimentos inadequados de trabalho humano. 
É importante registrar algumas limitações encontradas na abordagem proposta, que foram identificadas durante a execução deste projeto. As mais importantes são:

- Alto custo de aplicação da abordagem, em razão das muitas interações para se gerar e validar sucessivas versões de documentos;

- Dificuldade de reunir as pessoas mais adequadas em cada um dos encontros realizados e a geração de extensos volumes de gravações em áudio;

- Profissionais da Central de Regulação Médica gastaram um tempo considerável na familiarização e compreensão das técnicas e ferramentas adotadas;

- Não é possível garantir que todas as impropriedades do sistema de informação foram identificadas;

- Falta de um sistema computacional para apoiar todas as atividades da abordagem, o que provocou a adaptação de ferramentas gerais de outros contextos para a efetiva utilização nesta abordagem.

E, por fim, algumas carências percebidas ao longo deste estudo proporcionam a sugestão de alguns trabalhos futuros. Como uma continuação natural do projeto, outras técnicas de estudo podem ser aplicadas da seguinte maneira:

- A análise detalhada de todas as interfaces do sistema de informação por intermédio de técnicas de design e interação humano-computador;

- A identificação de problemas oriundos de procedimentos de trabalho humano por intermédio de técnicas de fatores humanos e engenharia cognitiva;

Adicionalmente, novas iniciativas de pesquisa e desenvolvimento podem ser recomendadas, tais como:

- O desenvolvimento de um ambiente integrado para suportar todas as etapas da abordagem, de modo a viabilizar a integração de todos os artefatos produzidos;

- Validação da abordagem em outros tipos de domínios.

Este trabalho apresentou uma abordagem interdisciplinar que, ao percorrer diversas áreas de conhecimento, possibilita uma compreensão mais abrangente do domínio de estudo e, portanto, ajuda na aquisição de um conhecimento não fragmentado sobre o mesmo. A sua articulação por várias áreas teóricas permitiu uma análise mais profunda dos problemas, a identificação de suas possíveis causas e conseqüências, e por isso forneceu mais subsídios para a elaboração de propostas de soluções.

Os resultados obtidos com a execução da abordagem proposta mostram a sua aplicabilidade no domínio de urgências médicas pré-hospitalares e encorajam experimentações em outros domínios.

\section{Agradecimentos}

Este projeto foi parcialmente financiado pela Fundação Carlos Chagas Filho de Amparo à Pesquisa do Estado do Rio de Janeiro (FAPERJ) e pela Coordenação de 
Aperfeiçoamento de Pessoal de Nível Superior (CAPES). Os autores gostariam de agradecer ao Programa de Pós-Graduação em Informática (PPGI) e ao Núcleo de Computação Eletrônica (NCE), ambos da Universidade Federal do Rio de Janeiro (UFRJ), pelo fornecimento da infra-estrutura necessária para a criação do Laboratório de Tratamento de Emergências.

\section{Referências Bibliográficas}

Borsato, G. B., Scalabrin E.E., Dias J. S. e Enembreck, F. (2006). "Sistema de Apoio à Tomada de Decisão para Atendimento Pré-Hospitalar”, In: CBIS'2006 - X Congresso Brasileiro de Informática em Saúde. Florianópolis.

Cappelli, C., Baião, F., Santoro, F. M., Hiendrike, H. S., Lopes, M. e Nunes, V. T. (2007). "Uma abordagem de construção de ontologia de domínio a partir do modelo de processos de negócio". In: 2nd Workshop on Ontologies and Metamodels in Software and Data Engineering (WOMSDE 2007), João Pessoa. SBBD/SBES. v. 1. p. 85-96.

Cunha, A. M. e Souza, G. Q. (2005). "Especificando Requisitos a Partir do Conceito de Processo de Trabalho", In: VII SIMPROS - Simpósio Internacional de Melhoria de Processo de Software, São Paulo.

Cunha, A. M. e Souza, G. Q. (2006). "O Conceito de Memória na Modelagem de Processos de Negócios para Gerar Requisitos de Sistemas de Informação", In: III SBSI - Simpósio Brasileiro de Sistemas de Informação, Curitiba.

Crandall, B., Klein, G. e Hoffman, R. (2006). “Working Minds: A Practitioner's Guide To Cognitive Task Analysis", The MIT Press, Cambridge, Massachusetts.

Davis, R. (2008). "ARIS Design Platform - Advanced Process Modelling And Administration", Springer.

Elliot, P. (2000). “An Approach to Integrated Rescue". QMC - Queensland Mining Council: Osborne Mines.

Jacobson. I., Ericsson, M e Jacobson, A. (1994). "The Object Advantage, Business Process Reengineering With Object Technology". Addison-Wesley Publishing Company, ACM Press.

Junior, J. e Valente, A. (2005). "A Logística no Serviço de Atendimento Móvel de Urgência (SAMU)", XXV Encontro Nacional de Engenharia de Produção, Porto Alegre. p. 4526-4532.

Lopes, S. e Fernandes, R. (1999). "Uma Breve Revisão do Atendimento Médico PréHospitalar", Medicina, Ribeirão Preto, outubro/dezembro. p. 381-387.

Ministério da Saúde (2006a). "Política Nacional de Atenção às Urgências", Série E, Legislação de Saúde, Brasília.

Ministério da Saúde (2006b). "Regulação Médica das Urgências", Série A, Normas e Manuais Técnicos, Brasília.

Novak, J. e Cañas, A. (2006). "The Theory Underlying Concept Maps And How To Construct Them", Florida Institute for Human And Machine Cognition. 
Object Management Group (2008), "Business Process Modeling Notation - OMG Avaible Specification". Disponível em: http://www.bpmn.org/. Acessado em: 25 de novembro de 2009.

Pfleeger, S. (2004). "Engenharia de Software”, Segunda Edição, Prentice-Hall.

Rational Unified Process (2000), Rational Unified Process Documentation. Disponível em: http://www.rational.com/rup/. Acessado em: 25 de Novembro de 2009.

Sharp, A. e McDermott, P. (2001). "Workflow Modeling - Tools For Process Improvement and Application Development", Artech House Publishers.

Sommerville, I. (2003). "Engenharia de Software”, Editora Pearson Addison Wesley, São Paulo.

Souza, A. P., Freitas, J. V. V. B., Cunha, A. M. e Campos, M. L. (2009). "Um Método de Modelagem de Processos para a Investigação de Problemas em Sistemas de Informação: Aplicação em uma Central de Regulação Médica”, In: V SBSI Simpósio Brasileiro de Informação, Brasília. p. 216-227.

Thiollent, M. (2003). "Metodologia da Pesquisa-Ação”, Cortez Editora. 